\title{
Parotidectomy and Facial Paralysis, A Retrospective Review at A Tertiary Care Hospital
}

\author{
Israr ud Din ${ }^{1}$, Muhammad Junaid ${ }^{1}$, Imran Khan ${ }^{1}$, Arshad Aziz ${ }^{2}$, Sakhawat Khan ${ }^{3}$, Aafia Afridi ${ }^{4}$, Ihtisham ul \\ $\mathrm{Haq}^{2}$ \\ ${ }^{1}$ Assistant Professor, Department of ENT, Head \& Neck Surgery, Khyber Medical College/ KTH, Peshawar, Pakistan \\ ${ }^{2}$ Registrar, Department of ENT, Head \& Neck Surgery, Khyber Medical College/ KTH, Peshawar, Pakistan \\ ${ }^{3}$ Senior Registrar, Department of ENT, Head \& Neck Surgery, Khyber Medical College/ KTH, Peshawar, Pakistan \\ ${ }^{4}$ Registrar, Department of Accident \& Emergency, Khyber Teaching Hospital, Peshawar
}

\begin{abstract}
A B STRACT
Background: Facial Nerve is in close proximity with parotid gland and encountered during parotid surgery. Facial nerve paralysis has 15 to $66 \%$ occurrence rate after parotidectomies. The objective of this study was to find out the frequency of facial paralysis resulting from superficial or total parotidectomies done forvarious parotid tumors.

Material and Methods: This retrospective study was conducted at the Department of ENT, Khyber Teaching Hospital, Peshawar from January 2018 to May 2020. A total of 203 patients were reviewed for data on demographics, parotidectomies, histopathology and facial paralysis. The information on facial paralysis was compared against various parameters.

Results: The mean age of the participants was $46.12 \pm 11.11$ years. The most common parotid tumor was pleomorphic adenoma (68.9\%) followed by mucoepidermoid carcinoma. 57 (28.07\%) patients showed facial paralysis with a higher rate of occurrence in total parotidectomy (40.90\%). Among 57 patients with facial paralysis, 6 (10.53\%) showed permanent facial paralysis.

Conclusion: Tendency of permanent facial paralysis is high with total parotidectomies. Female population and elderly have a slightly higher rate of facial paralysis. The duration of procedure has no effect on the occurrence of facial paralysis.

Keywords: Facial paralysis, Mucoepidermoid carcinoma, Parotid tumors, Pleomorphic adenoma, Parotidectomy.

Authors' Contribution:

${ }^{4}$ Conception; Literature research;

manuscript design and drafting; ${ }^{1,2,}$ Critical

analysis and manuscript review; ${ }^{3}$ Data

analysis; Manuscript Editing.

\section{Correspondence:}

Muhammad Junaid

Email: drjunaident@gmail.com

\section{Article info:}

Received: April 17, 2021

Accepted: September 19, 2021
\end{abstract}

Cite this article. Din IU, Junaid M, Khan I, Aziz A, Khan S et al. Parotidectomy and Facial Paralysis, A Retrospective Review at A Tertiary Care Hospital. J Islamabad Med Dental Coll.

Funding Source: Nil

Conflict of Interest: Nil 2021; 10(3): 164-168. Doi: 10.35787/jimdc.v10i3.705

\section{Introduction}

Parotid pathologies, especially benign and malignant tumors mostly require surgery as the modality of treatment which may be superficial, subtotal or total parotidectomy. Parotidectomy of any kind carries a high risk of damage to the facial nerve. The less conservative procedures warrant a lesser chance of recurrence but have a higher rate of complications. In fact, one of the most common complications associated with the procedure tends to be facial paralysis, either temporary or permanent. Temporary facial paralysis occurs at a rate of $15 \%$ to $66 \%$ while permanent facial paralysis is relatively infrequent $2.5 \%$ to $5 \% .{ }^{1}$ Neuropraxia has been reported in approximately $8 \%$ to $46 \%$ of parotidectomies done for benign parotid pathologies. $^{2}$ 
To date, facial paralysis remains one of the greatest fears of the procedure for the patient where they are anxious about ending up with facial dysfunction upon waking from the procedure. This happens to be one of the reasons for patients with massive parotid swellings to appear at a late stage for medical consultation.

The incidence of facial paralysis resulting from parotidectomies has shown a significant decrease over the past few decades. This decline in facial weakness is mainly attributed to advancement in the field of bioinformatics and bioengineering with instruments like nerve monitors providing the surgeon with vital information regarding imminent danger in the proximity of the facial nerve. ${ }^{3,4}$

The objective of this study was to assess and compare the post operative occurrence rate of facial paralysis in patients with benign and malignant parotid pathologies in order to reflect on the need for improvement in surgical practice to reduce its risk.

\section{Material and Methods}

This retrospective study was conducted at the Department of ENT, Khyber Teaching Hospital after approval from the institutional ethical review board. Duration of the study was two and a half years from January 2018 to May 2020. A sample size of 203 was calculated with Open Epi sample size calculator version 3.01 , using $80 \%$ power of study, $95 \%$ confidence interval, $5 \%$ margin of error and $15.6 \%$ anticipated frequency of facial paralysis in parotidectomies. ${ }^{1}$ Sampling technique was nonprobability convenient.

Records of all patients approaching the outpatient Department of ENT with parotid swelling showing FNAC report of neoplastic activity from January 2018 to May 2020 were included in the study. Patients were excluded on the basis of having either previous surgery, pre-operative facial paralysis or insufficient data in their records. The information acquired from the clinical records comprised of demographic data, histopathological outcome, type of procedure performed and occurrence of post-operative facial paralysis. Furthermore, information about the facial nerve such as degree of facial paralysis, duration of facial paralysis and degree of recovery was also recorded.

Parotidectomy was performed in all the patients. The extent of procedure was either superficial or deep, depending upon the nature of the disease. Identification of the facial nerve was done by employing an antegrade technique. This was achieved by using 3 surgical landmarks; tragal pointer, styloid process and posterior belly of digastric muscle. No nerve stimulator or monitor had been used in any of the cases. Functional integrity of the facial nerve was monitored visually by the assisting surgeon. At the end, wound and skin closure was performed using polyglactin 910 [Vicryl ${ }^{\circledR}$ Johnson-Johnson].

Data analysis was performed using SPSS 26.0. Qualitative data was presented as number and percentages. Quantitative data was summarized as means and standard deviations. Chi-square test was used to determine the association of facial paralysis with age, gender, type and duration of surgery. Moreover, association of type of facial paralysis with type of parotidectomy was also analyzed. The significance level was set at $p<0.05$.

\section{Results}

Among the total sample of 203 patients, the number of male patients was 110 (54.18\%) and female patients was 93 (45.82\%) giving a male to female ratio of about 1.18:1. Mean age of the patients was $46.12 \pm 11.11$ years (range:24-69). The mean age of males was $46.8 \pm 11.19$ years and females $45.3 \pm 11.02$ years. Statistics related to age and gender are given. (Table I) 


\begin{tabular}{|c|c|c|c|}
\hline Age & Benign & Malignant & Total \\
\hline $\begin{array}{c}30 \text { years and } \\
\text { below } \\
\text { Male } \\
\text { Female }\end{array}$ & $\begin{array}{l}4 \\
4\end{array}$ & $\begin{array}{l}2 \\
1\end{array}$ & $\begin{array}{l}6(2.9 \%) \\
5(2.46 \%)\end{array}$ \\
\hline $\begin{array}{c}31-45 \text { years } \\
\text { Male } \\
\text { Female }\end{array}$ & $\begin{array}{l}28 \\
43 \\
\end{array}$ & $\begin{array}{c}18 \\
6 \\
\end{array}$ & $\begin{array}{l}46(22.66 \%) \\
49(24.13 \%) \\
\end{array}$ \\
\hline $\begin{array}{c}46-60 \text { years } \\
\text { Male } \\
\text { Female }\end{array}$ & $\begin{array}{l}32 \\
19 \\
\end{array}$ & $\begin{array}{l}7 \\
7 \\
\end{array}$ & $\begin{array}{l}39(19.21 \%) \\
26(12.81 \%)\end{array}$ \\
\hline $\begin{array}{c}\text { Above } 60 \text { years } \\
\text { Male } \\
\text { Female }\end{array}$ & $\begin{array}{l}14 \\
10 \\
\end{array}$ & $\begin{array}{l}5 \\
3 \\
\end{array}$ & $\begin{array}{l}19(9.36 \%) \\
13(6.40 \%)\end{array}$ \\
\hline Total & $\begin{array}{c}154 \\
(75.86 \%)\end{array}$ & $\begin{array}{c}49 \\
(24.14 \%)\end{array}$ & 203 \\
\hline
\end{tabular}

Among 203 patients, large number of patients 159(78.32\%) underwent a superficial parotidectomy and $44(21.68 \%)$ total conservative surgery. Among patients having superficial parotidectomy, $24.52 \%$ developed temporary facial palsy which was resolved within two months after the procedure. Out of patients who underwent total conservative type of surgery, 12(27.27\%) developed temporary and 6 (13.63\%) permanent facial palsy. (Table II)

The duration of the procedure from first incision to closure of the wound ranged from 75 minutes to 150 minutes with an average of about $134.3 \pm 12.2$ minutes.

\begin{tabular}{|l|l|l|l|l|}
\hline \multicolumn{4}{|l|}{ Table II: Data of facial paralysis reported in study } \\
participants $(\mathbf{n}=\mathbf{2 0 3})$
\end{tabular}

A significant association of facial palsy was found with increased age and female gender. The association of facial palsy with type and duration of surgery was non-significant. (Table III)

The study found a strong association between type of facial paralysis and the type of procedure performed. It showed a higher occurrence of permanent facial paralysis in superficial parotidectomy. (Table IV)

Table III: Association of facial palsy with age, gender, age and duration of surgery $(n=203)$

\begin{tabular}{|l|l|l|l|}
\hline \multirow{2}{*}{ Variable } & \multicolumn{2}{|c|}{ Facial Palsy } & \\
\cline { 2 - 4 } & $\begin{array}{l}\text { Absent } \\
(\mathrm{n}=146) \\
\mathrm{n}(\%)\end{array}$ & $\begin{array}{l}\text { Present } \\
(\mathrm{n}=57) \\
\mathrm{n}(\%)\end{array}$ & P value \\
\hline Age & & & \\
\hline $\begin{array}{l}\text { Above } \\
\text { years }\end{array}$ & $19(13.01)$ & $22(38.59)$ & \\
\hline 46-60 years & $46(31.51)$ & $19(33.33)$ & 0.03 \\
\hline 31-45 years & $73(50)$ & $1322.80)$ & \\
\hline $\begin{array}{l}30 \text { years and } \\
\text { below }\end{array}$ & $8(5.48)$ & $3(5.26)$ & \\
\hline Gender & $60(41.09)$ & $33(57.89)$ & 0.04 \\
\hline Female & $86(58.90)$ & $24(42.10)$ & \\
\hline Male & & & \\
\hline Surgery & $30(20.55)$ & $13(22.81)$ & 0.34 \\
\hline $\begin{array}{l}\text { Total } \\
\text { Parotidectomy }\end{array}$ & $116(79.45)$ & $44(77.19)$ & \\
\hline $\begin{array}{l}\text { Superficial } \\
\text { Parotidectomy }\end{array}$ & & & \\
\hline $\begin{array}{l}\text { Duration of } \\
\text { Surgery }\end{array}$ & $41(28.08)$ & $14(24.56)$ & 0.43 \\
\hline$\leq 120$ minutes & $105(71.91)$ & $43(75.43)$ & \\
\hline$>120$ minutes & & & \\
\hline
\end{tabular}

Table IV: Association of degree of Facial Palsy with type of surgery $(n=57)$

\begin{tabular}{|l|l|l|l|}
\hline \multirow{2}{*}{} & \multicolumn{2}{|c|}{ Facial Palsy } & $\begin{array}{l}p \\
\text { value }\end{array}$ \\
\cline { 2 - 4 } & $\begin{array}{l}\text { Temporary } \\
(\mathrm{n}=51) \mathrm{n}(\%)\end{array}$ & $\begin{array}{l}\text { Permanent } \\
(\mathrm{n}=6) \mathrm{n}(\%)\end{array}$ & \\
\hline $\begin{array}{l}\text { Type of } \\
\text { Surgery }\end{array}$ & & & \\
\hline $\begin{array}{l}\text { Total } \\
\text { Parotidectomy }\end{array}$ & $12(23.53)$ & $0(0)$ & \\
\hline $\begin{array}{l}\text { Superficial } \\
\text { Parotidectomy }\end{array}$ & $39(76.47)$ & $6(100)$ & 0.001 \\
\hline
\end{tabular}


According to histopathological analysis, total 154 (75.86\%) cases reported as benign while the remaining 49 (24.14\%) reported as malignant. Among benign cases, Pleomorphic Adenoma was found in 140 (68.9\%) patients followed by Warthin's tumor 6 (3\%). In malignant cases, mucoepidermoid was the most common tumor accounting for 37 cases (18.1\%) followed by carcinoma Ex Pleomorphic adenoma, 3 cases (1.5\%).

\section{Discussion}

Parotid tumors are quite uncommon and comprise of about $0.8 \%$ of all the tumors in the body with an annual global incidence of about 3-4/100,000 people. ${ }^{5}$ At the same time, they make up a $2-10 \%$ fraction of the head and neck tumors. ${ }^{6}$ Surgical procedures of the parotid usually end with a variety of complications among which transient facial paralysis is the most common. Hence, one of the most important concerns during the procedure is to maintain anatomical and functional integrity of the facial nerve. In order to ensure this, an important step of the procedure is facial nerve identification which is done using either of the two techniques; antegrade or retrograde techniques. The antegrade technique is mostly practiced in majority of the facilities. ${ }^{7,8}$

This study of 203 patients showed a male to female ratio of 1.18:1 with the mean age at which parotidectomy was performed to be $46.12 \pm 11.11$ years. The male to female ratio is comparable of those reported by Siddiqui1, Hussain2 and Thamim6 that were $1: 1, \quad 1.2: 1$ and $1.3: 1$ respectively. Ali9 reported a mean age of 45.75 years while Rahman ${ }^{10}$ and Siddiqui ${ }^{1}$ reported ages of 40.63 and 38.75 years respectively.

A majority of the patients in this study had gone through superficial parotidectomy amounting to be $78.32 \%$ while only $21.68 \%$ had total parotidectomies. However, the fraction of patients getting facial paralysis after parotidectomy was
$28.07 \%$ compared to the $25.71 \%, 28.08 \%$ and $36.66 \%$ reported in studies by Siddiqui ${ }^{1}$, Musani ${ }^{10}$ and Rahman $^{11}$ respectively. In this study, the occurrence of facial paralysis resulting from superficial parotidectomy was $24.52 \%$ compared to $40.90 \%$ with total parotidectomies. This was significantly less than the incidence of $34.72 \%$ and $50 \%$ with superficial and total parotidectomies respectively, reported by Rahman et al. ${ }^{10}$

Histopathology of these tumors shows a variety of benign and malignant types. According to the literature, almost $80-85 \%$ of the parotid tumors are benign in nature while the remaining $15-20 \%$ are malignant. ${ }^{10}$ The percentage of benign tumors found in this study is comparable to the $74 \%, 81.2 \%$ and $82.6 \%$ reported by Ali $^{9}$, Siddiqui ${ }^{1}$ and Musani ${ }^{11}$, respectively.

Various methods have been developed to check for post operative facial nerve paralysis, the most effective one is subjective and objective clinical assessment. ${ }^{12}$ Children are more at risk to develop facial nerve palsy due to variable location with respect to deep lobe pathologies and small size of the nerve and gland. ${ }^{13}$ Carter JM, reported 94\% temporary and $2 \%$ permanent nerve palsy in children with the mean age of 8.3 years after being operated as compared to this study. ${ }^{14}$ Experience of the surgeon, pre-operative imaging and intraoperative nerve monitoring greatly reduces the risk of nerve palsy ${ }^{15}$ but in this study, only magnifying lups and operative microscope were used. Study of Bovenzi CD et al shows much improved results with $3.7 \%$ facial nerve palsy as they performed reconstructive measures of the nerve, like anastomosis, interpositional grafting and nerve transfer to restore functions of the nerve that we did not offer to our patients. ${ }^{16}$ For patients with malignant tumors, large in size, hard fixed with deep lobe involvement, facial nerve injury remains more common. Duration of surgical procedure have direct effect on facial nerve functions. Bittar RF, reported temporary facial nerve palsy in $16.6 \%$ and no permanent as most of the surgeries were 
performed by senior surgeons. ${ }^{17}$

\section{Conclusion}

Facial paralysis is more common with total parotidectomies. Female gender and age above 60 years are more likely to have facial paralysis while the duration of the procedure shows no association. Early identification and careful exploration of the facial nerve is the key to preserving facial nerve function.

\section{References}

1. Siddiqui $A H$, Shakil S, ur Rahim D, Shaikh IA. Post parotidectomy facial nerve palsy: A retrospective analysis. Pak J med Sci. 2020;36(2):126-130. Doi: 10.12669/pjms.36.2.1706

2. Thahim K, Udaipurwala IH, Kaleem M. Clinical manifestations, treatment outcome and postoperative complications of parotid gland tumoursan experience of 20 cases. J Pak Med Assoc. 2013;63(12):1472-5. PMID: 24397087

3. Ruohoalho J, Mäkitie AA, Aro K, Atula T, Haapaniemi $A$, Keski-Säntti $\mathrm{H}$, et al. Complications after surgery for benign parotid gland neoplasms: a prospective cohort study. Head \& Neck. 2017;39(1):170-6. Doi: 10.1002/hed.24496

4. Sethi N, Tay P, Scally A, Sood S. Stratifying the risk of facial nerve palsy after benign parotid surgery. The journal of Laryngology \& Otology. 2014;128(2):15962. Doi: $10.1017 / \mathrm{S} 0022215113003502$

5. Stathopoulos P, Igoumenakis D, Smith WP. Partial superficial, superficial and total parotidectomy in the management of benign parotid gland tumors: a 10-year prospective study of 205 patients. Journal of Oral and Maxillofacial Surgery. 2018 1;76(2):455-9. Doi: 10.1016/j.joms.2017.06.018

6. Hussain A, Farid A, Uddin W. Superficial Parotidectomy by Retrograde approach through Marginal Mandibular Nerve Dissection. Journal of Islamabad Medical \& Dental College. 2019;8(4):1715. Doi: $10.35787 /$ jimdc. v8i4.431

7. Anjum K, Revington $P$, Irvine GH. Superficial parotidectomy: antegrade compared with modified retrograde dissections of the facial nerve. The British journal of Oral and Maxillofacial Surgery. 2008;46(6):433-4. Doi: 10.1016/j.bjoms.2008.03.018

8. Yuan $X$, Gao Z, Jiang $H$, Yang $H$, Lv W, Wang Z, et al.
Predictors of facial palsy after surgery for benign parotid disease: multivariate analysis of 626 operations. Journal for the sciences and specialties of the Head and Neck. 2009;31(12):1588-92. Doi: 10.1002/hed.21134

9. Ali NS, Nawaz A, Rajput S, Ikram M. Parotidectomy: a review of 112 patients treated at a teaching hospital in Pakistan. APJCP. 2010;11(4):1111-3. PMID: 21133633

10. Rahman M, Alam M, Joarder A. Study of the Nerve Injury in Parotid Gland Surgery. Nepalese Journal of ENT, Head and Neck Surgery. 2011;2(1):17-9. Doi: 10.3126/njenthns.v2i1.6779

11. Musani MA, Zafar A, Suhail Z, Malik S, Mirza D. Facial nerve morbidity following surgery for benign parotid tumours. J Coll Physicians Surg Pak. 2014;24(8):569-72. PMID: 25149836

12. Wang $\mathrm{T}$, Zhang $\mathrm{S}$, Dong J, Liu LA, Yu H. Automatic evaluation of the degree of facial nerve paralysis. Multimedia Tools and Applications. 2016 Oct 1;75(19):11893-908. Doi: 10.1007/s11042-0152696-0

13. Maddalozzo J, Johnston DR, Isaac A, Bhushan B, Rastatter JC. Displacement of the Facial Nerve by Deep Parotid Lobe Lesions in the Pediatric Population. Laryngoscope investigative otolaryngology. 2019;4(5):550-3. Doi: 10.1002/lio2.302

14. Carter JM, Rastatter JC, Bhushan B, Maddalozzo J. Thirty-day perioperative outcomes in pediatric parotidectomy. JAMA Otolaryngology-Head \& Neck Surgery. 2016;142(8):758-62. Doi: 10.1001/jamaoto.2016.1031

15. Jin H, Kim BY, Kim H, Lee E, Park W, Choi S, et al. Incidence of postoperative facial weakness in parotid tumor surgery: a tumor subsite analysis of 794 parotidectomies. BMC surgery. 2019;19(1):1-8. Doi: 10.1186/s12893-019-0666-6

16. Bovenzi CD, Ciolek P, Crippen M, Curry JM, Krein H, Heffelfinger $R$, et al. Reconstructive trends and complications following parotidectomy: incidence and predictors in 11,057 cases. Journal of Otolaryngology-Head \& Neck Surgery. 2019 Dec 1;48(1):64. Doi: 10.1186/s40463-019-0387-y

17. Bittar RF, Ferraro HP, Ribas MH, Lehn CN. Facial paralysis after superficial parotidectomy: analysis of possible predictors of this complication. Brazilian journal of otorhinolaryngology. $2016 \mathrm{Jul}$ 1;82(4):447-51. Doi: 10.1016/j.bjorl.2015.08.024 